\title{
Bir Lojistik Firması için Çok Ölçütlü Karar Verme Yöntemleri İle İç Anadolu Bölgesinde Depo Yeri Seçimi
}

\author{
Ömer Şeker ${ }^{1}$, Hacı Mehmet Alakaş² \\ ${ }^{1}$ Öğr.Gör., Kırşehir Ahi Evran Üniversitesi, Mucur MYO, Lojistik Programı, omerseker@ahievran.edu.tr \\ ${ }^{2}$ Dr. Öğr. Üyesi, Kırıkkale Üniversitesi, Mühendislik Fakültesi, Endüstri Mühendisliği Bölümü, \\ hmalagas@kku.edu.tr
}

\section{Özet}

Lojistik operasyonlarının stratejik önemi giderek artmaktadır. Bundan dolayı şirketleri, rakipleri ile rekabet edebilmeleri için etkin lojistik kararlar almaya itmektedir. Depolar için en iyi yerlerin seçilmesi, uzun vadeli ve geri dönüşü zor bir karardır. Bu karar sürecinde birçok kriter etkindir. Bu karar; dağıtım stratejisini de etkileyerek müşteri memnuniyeti ve lojistik maliyetler üzerinde önemli rol oynar. Bu çalışmada bir ev aletleri firması için depo yeri seçim problemi ele alınmıştır. Firma için, İç Anadolu bölgesinde bir merkezi depo yeri seçimi yapılmıştır. Problemin çözümünde, çok ölçütlü karar verme yöntemlerinden Analitik Hiyerarşi Prosesi (AHP), TOPSIS ve PROMETHEE yöntemleri kullanılmıştır. Belirlenen 6 kriterin ağırlıkları AHP ile hesaplanarak, alternatifler bu 3 yönteme göre sıralanmıştır. Bu yöntemlerin yakın sonuç verdikleri görülmüş ve 5 alternatiften en uygun olanı seçilmiş̧ir.

Anahtar kelimeler: Çok Ölçütlü Karar Verme, Depo Yeri Seçimi, AHP, TOPSIS, PROMETHEE

\section{Selection of Warehouse Location in Central Anatolia Region with Multi Criteria Decision Making Methods for a Logistics Company}

\begin{abstract}
The strategic importance of logistics operations is increasing. Therefore, it drives companies to make efficient logistics decisions in order to compete with their competitors. Choosing the best locations for warehouses is a long-term and irreversible decision. Many criteria are effective in this decision process. This decision; It also plays an important role on customer satisfaction and logistics costs by affecting the distribution strategy. In this study, the problem of choosing a warehouse location for a home appliance company is discussed. A central warehouse location was selected for the company in the Central Anatolia region. In the solution of the problem, Analytical Hierarchy Process (AHP), TOPSIS and PROMETHEE methods were used. The weights of the 6 criteria were calculated by AHP and alternatives were listed according to these 3 methods. These methods were found to give close results and the most appropriate one was chosen.
\end{abstract}

Key words: Multi Criteria Decision Making, Warehouse Location Selection, AHP, TOPSIS, PROMETHEE

\section{Giriş}

İşletmeler, gelişen dünyada pazara ayak uydurmak ve rekabet edebilmek için gün geçtikçe maliyetlerine daha ciddi bir şekilde odaklanmaktadır. Tüm maliyetlerin içerisinde lojistik maliyetleri de önemli bir yer işgal etmektedir. Taşıma ve depolama maliyetleri lojistik maliyetler içerisinde en büyük paya sahip iki maliyettir. İşletmelerin ürettiği ürünleri doğru bir şekilde

*Corresponding author: Address: Kırşehir Ahi Evran Üniversitesi, Mucur Meslek Yüksekokulu, Lojistik Programı 40500, Kırşehir TURKEY. E-mail address: omerseker@ ahievran.edu.tr, Phone: +903862805550 
depolayabilecekleri yerin seçimi, birçok faktörün sürece dâhil edilerek, dikkatli ve etkin şekilde karar verilmesi gereken bir problemdir. Potansiyel depo yerlerinin uygun bir şekilde değerlendirilerek seçimin yapılması işletmeler için önemli bir aşamadır.

Depo yeri seçiminde matematiksel modeller, ağırlık merkezi yöntemi, etken-puan yöntemi, çok ölçütlü karar verme yöntemleri gibi metotlar kullanılmaktadır. Çok ölçütlü karar verme yöntemi, farklı kriterleri kullanarak alternatifleri seçmek ya da siralamak için alternatiflerin değerlendirilmesi olarak ifade edilebilir [1]. Çok sayıda kriter değerlendirilerek, alternatiflerden en iyisinin seçilmesini sağlayan bu yöntemler sıklıkla kullanılır. Bu yöntemler, gerçek hayatta ki karmaşı problemlerin çözümünde önemli avantaj sağlar.

Bu çalışmada, beyaz eşya ve küçük ev aletleri sektöründe hizmet veren müşterileri için lojistik hizmet sağlayıcısı olan firmanın ÇÖKV teknikleri kullanılarak, Ankara, Konya, Aksaray, Kırıkkale ve Kayseri alternatif illerinden birinde kurulacak depo için uzman kişilerce belirlenmiş ve literatürde yer alan kriterler ş̧ı̆̆ında depo yerine karar verilmesi amaçlanmaktadır. Kriterler ise arazi/depo fiyatları, kalifiye işgücü, müşterilere (bayi veya nihai tüketici) yakınlık, ulaşım ağı ve erişilebilirlik, altyapı ve kamu ve yönetim faktörleri olarak belirlenmiş̧ir.

Çalışmanın ikinci bölümünde literatür araştırmasına yer verilmiştir. Üçüncü bölümde kullanılacak ÇÖKV yöntemleri hakkında bilgi verilmiş, dördüncü bölümde depo yeri seçiminin önemine değinilmiştir. Beşinci bölümde uygulamadan ve son bölümde çalışmanın sonuçlarından bahsedilmiştir.

\section{Literatür Araştırması}

Literatürde depo yeri seçimiyle alakalı birçok çalışma mevcuttur. Bu çalışmalardan bazılarına aşağıda yer verilmiştir.

Korpela ve Tuominen [2], Analitik Hiyerarşi Prosesi (AHP) yöntemini kullanarak bir karar destek sistemi geliştirmişlerdir. Chen [3], dağıtım merkezi yer seçimi problemi için yeni bir ÇKKV yaklaşımı geliştirmiştir. Kahraman vd. [4], nicel ve nitel etkenleri baz alarak bulanık çok kriterli grup karar verme yöntemiyle en iyi alternatifi bulmaya çalışmışlardır. Chen [5], depo yeri seçiminde ağırlık merkezi ve AHP yöntemlerini kullanmıştır. Birsel ve Cerit [6], depo yeri seçim problemini lojistik işletmelerin kuruluş yeri seçim problemlerinde arazi faktörünün etkisi bağlamında ele almıştır. Durmuş [7], İstanbul'da lojistik depoların dağılımı ve depo yeri seçimini etkileyen faktörleri ele almıştır. Demirel vd. [8], Choquet Integral kullanarak, maliyet, iş karakteristikleri, altyapı, pazar ve vergi teşvikleri gibi kriterlerle alternatifleri değerlendirmişlerdir. Özcan vd. [9], TOPSIS, ELECTRE ve Gri Teori kullanarak çok ölçütlü bir karar verme modeli oluşturmuş ve depo yeri seçimine ek olarak üretim tesisi yer seçimi, depo yerleşimi gibi alanlara da yer vermişlerdir. Ashrafzadeh vd. [10], İran'daki bir şirketin depo yeri seçimi problemini bulanık TOPSIS yöntemini kullanarak ele almışlardır. Çaka [11], depo yeri seçimi için Choquet Integrali yöntemini kullanmıştır. Aktepe ve Ersöz [12], bir döküm firması için AHP, VIKOR ve MOORA yöntemlerini kullanarak, 11 alternatif ilden 3 tanesinde depo kurulması kararı almışlardır. Karmaker ve Saha [13], depo yer seçimi probleminde Bulanık AHP kullanılarak ağırlıkları belirlemiş, TOPSIS ve Bulanık TOPSIS ile de alternatiflerin sıralamasını 
yapmışlardır. Cömert ve Yener [14], bir gıda firması için 4 ana kriteri Bulanık AHP yönteminde ele alınarak depo yeri seçimi üzerine durmuşlardır. Dey vd. [15], depo yerinin seçiminde Bulanık TOPSIS, Bulanık SAW ve Bulanık MOORA yöntemlerini kullanmışlardır. Emeç [16], bir süpermarketin depo yer seçimi problemine Stokastik Analitik Hiyerarşi Prosesi, Bulanık MOORA ve Bulanık VIKOR yöntemlerini kullanarak çözüm aramışlardır. Gołda ve Izdebski [17], depo için en uygun yerin seçiminde genetik algoritma yöntemini kullanmışlardır. Gül ve Eren [18], bir kamu sektöründe depo yeri seçimine yönelik olarak analitik hiyerarşi prosesi ile hedef programlama yöntemlerini kullanarak sonuçlar elde etmişlerdir. Yavuz [19], depo yeri seçiminde Gri Sistem Teorisi ve VIKOR yöntemlerini kullanmıştır. Singh vd. [20], İran'da ki bir otomotiv firması için dört alternatif yerden en uygun depo yeri seçimini için AHP yöntemini kullanmışlardır.

Bu çalışmada da AHP, TOPSIS ve PROMETHEE bütünleşik yöntemleri kullanılarak en uygun depo yer seçimine karar verilmiştir.

\section{3. Çok Ölçütlü Karar Verme Yöntemleri}

Optimizasyon problemlerinde kullanımı yaygın olan çok ölçütlü karar verme yöntemleri, en iyi alternatifin seçiminde, kriterler ile alternatifler arasında karşılaştırma ve sıralamaya dayalı yöntemlerdir. Bu çalışmada kullanılan yöntemler; AHP, TOPSIS ve PROMETHEE'dir.

\section{Analitik Hiyerarşi Prosesi (AHP)}

Analitik Hiyerarşi Prosesi, Thomas L. Saaty [21] tarafından 1977 yıllında geliştirilen ve karar verme problemlerinin çözümünde kullanılan bir yöntemdir. AHP, problemleri hiyerarşik bir yapıda ele alan ve ikili karşılaştırma mantığına dayanan çok kriterli karar verme tekniğidir [22].

AHP yönteminin uygulama adımları şu şekildedir:

1. Hiyerarşik yapının oluşturulması

2. Her bir kritere göre alternatiflerin ve kriterlerin kendi içerisinde ikili karşılaştırmalarının yapılmas1

3. Normalleştirme ve göreli önem ağırlıklarının hesaplanması

4. Tutarlılık oranının hesaplanmas1

5. Her bir kriterin $\mathrm{M}$ alternatif için önem ağırlıklarının hesaplanması

6. Alternatiflerin ağırlıklarının belirlenmesi

\section{TOPSIS Yöntemi}

Hwang ve Yoon tarafından 1981 yılında geliştirilen TOPSIS yöntemi, alternatiflerin sıralanmasında en kolay ve etkin kullanılabilen yöntemlerden biridir [23]. TOPSIS tekniği, kolay anlaşılır olmasından dolayı birçok alanda kullanılmaktadır. TOPSIS yöntemi ile karar verilirken pozitif ideal çözüme en yakın ve negatif ideal çözüme de en uzak olan alternatifin seçilmesi gerekir [24].

TOPSIS yöntemi aşamaları: 
1. Karar matrisinin (A) oluşturulması

2. Standart karar matrisinin (R) oluşturulması

3. Ağırlıklı normalleştirilmiş karar matrisinin (V) oluşturulması

4. Pozitif ideal $\left(\mathrm{A}^{+}\right)$ve negatif ideal $\left(\mathrm{A}^{-}\right)$çözümlerin oluşturulması

5. Ayrım ölçülerinin hesaplanması

6. İdeal çözüme göreli yakınlığın hesaplanması

\section{PROMETHEE Yöntemi}

PROMETHEE yöntemi 1982 yılında Brans [25] tarafından geliştirilmiş çok kriterli bir öncelik tayin etme metodudur. PROMETHEE yöntemi, diğer çok ölçütlü karar verme yöntemlerine göre basit bir yöntemdir. PROMETHEE yöntemi 7 adımdan oluşmaktadır [26].

1. Veri matrisinin oluşturulması

2. Kriterler için tercih fonksiyonlarının belirlenmesi

3. Ortak tercih fonksiyonlarının belirlenmesi

4. Tercih indekslerinin belirlenmesi

5. Alternatifler için pozitif $\left(\Phi^{+}\right)$ve negatif $\left(\Phi^{-}\right)$üstünlükler belirlenmesi

6. PROMETHEE I ile alternatifler için kısmi önceliklerin belirlenmesi

7. PROMETHEE II ile alternatifler için tam önceliklerin belirlenmesi

\section{Depo Yeri Seçimi}

Depo yeri seçimi, sürekli artan müşteri taleplerinden dolayı işletmeler açısından önemli bir problemdir. Bu talebi karşılayacak depoların varlığı, işletmeler açısından ciddi bir maliyet unsurudur. Bu yüzden depo yer seçimi kararı etkisi uzun yıllar sürecek stratejik bir karar olup kârlılık üzerinde son derece önemli etkileri olacaktır [27].

Lojistik maliyetler incelendiğinde taşıma, stok ve depolama maliyetleri temel maliyetler olarak karşımıza çıkmaktadır. Depo yer seçiminin ne kadar isabetli yapıldığıyla ilişkili olarak bu maliyetler artabilir veya azalabilir.

Depo yeri seçiminde amaç, maliyetleri en aza indirmek ve müşteri memnuniyet seviyesini en üst seviyeye çıkarmak olduğu için, hızlı ve zamanında teslimat, firmaları rakiplerinden bir adım öne geçirmektedir.

Deponun kurulacağı bölgedeki işgücü maliyetleri ve kalifiye işgücü, maliyetin yanı sıra verilecek olan hizmet kalitesini doğrudan etkileyeceğinden önemli faktörler olarak karşımıza çıkmaktadır. Ek olarak ulaşım ağının gelişmiş olması, depo yerine karar vermede önemli bir etken olacaktır. Özellikle karayolu ağının, teslimatların müşterilere hızlı ve güvenle yapılabileceği bir imkân sağlaması ve alternatifler sunması beklenir.

\section{Uygulama}

Problemin çözümünde görev alacak ekip, lojistik firmasının yurtiçi dağıtım departmanındaki uzman kişilerden oluşmaktadır. İç Anadolu Bölgesi'nde büyük bir depoya ihtiyaç olduğu kararlaştırıldıktan sonra, alternatif iller ve kriterler belirlenmiştir. Literatürden de faydalanılan bu 
süreçte, kriter sayısı önemlilik durumuna göre 6'ya ve alternatif il sayısı da 5'e indirilerek çözüm amaçlanmıştır.

\subsection{Problemin tanımı}

Üretim yeri Tekirdağ Çerkezköy’de olan firma, siparişleri İç Anadolu Bölgesi'ndeki bayilerine ve nihai müşterilerine daha hızlı ulaştırmak amacıyla 20 bin metrekare alana sahip bir depo kurulumu için en uygun yerin seçimini irdelemektedir. Hali hazırda lojistik firmasının Ankara, Eskişehir, Kayseri, Konya ve Aksaray’da aktarma merkezi bulunmaktadır ve buralardan da dağıtım sürecine destek verileceği düşünülerek karar verilmesi amaçlanmıştır.

\subsection{Verilerin toplanmast}

Problemle ilgili nicel veriler lojistik firmasından oransal olarak alınmıştır. Özellikle müşterilere yakınlık kriteri için önceki yıl teslimat verileri dikkate alınarak bölgenin ağırlık merkezi hesaplanmıştır.

\subsection{Kriterlerin belirlenmesi}

İç Anadolu Bölgesi'nde depo yeri seçimi problemi için, lojistik firmasından; lojistik direktörü, yurtiçi dağıtım yönetmeni ve İstanbul depo müdüründen oluşan ekip tarafindan literatürde de karşılığ1 olan [7, 8, 10, 14, 16, 19, 28] kriterler belirlenmiştir. Deponun ve yapılacak lojistik faaliyetlerin gereklerine uygun arazi/depo fiyatları (K1), kalifiye işgücü (K2), müşterilere (bayi veya nihai tüketici) yakınlık (K3), ulaşım ağı ve erişilebilirlik (K4), altyapı (K5) ve kamu ve yönetim faktörleri (K6) kriterleri baz alınarak depo yerinin seçimine karar verilecektir.

\subsection{Alternatiflerin belirlenmesi}

Kriterlerin belirlenmesinde çalışan ekip tarafından alternatifler ilin imkanları ve ağırlık noktası prensibine göre 5'e indirilmiş ve Ankara, Konya, Aksaray, Kırıkkale ve Kayseri olarak belirlenmiştir.

\subsection{Problemin Çözümü}

Problemin çözümünde çok ölçütlü karar verme yöntemlerinden yararlanılmıştır.

\subsubsection{AHP Yöntemi ile Problemin Çözümü}

Problemin hiyerarşik gösterimi aşağıdaki şekilde ifade edilmiştir. 


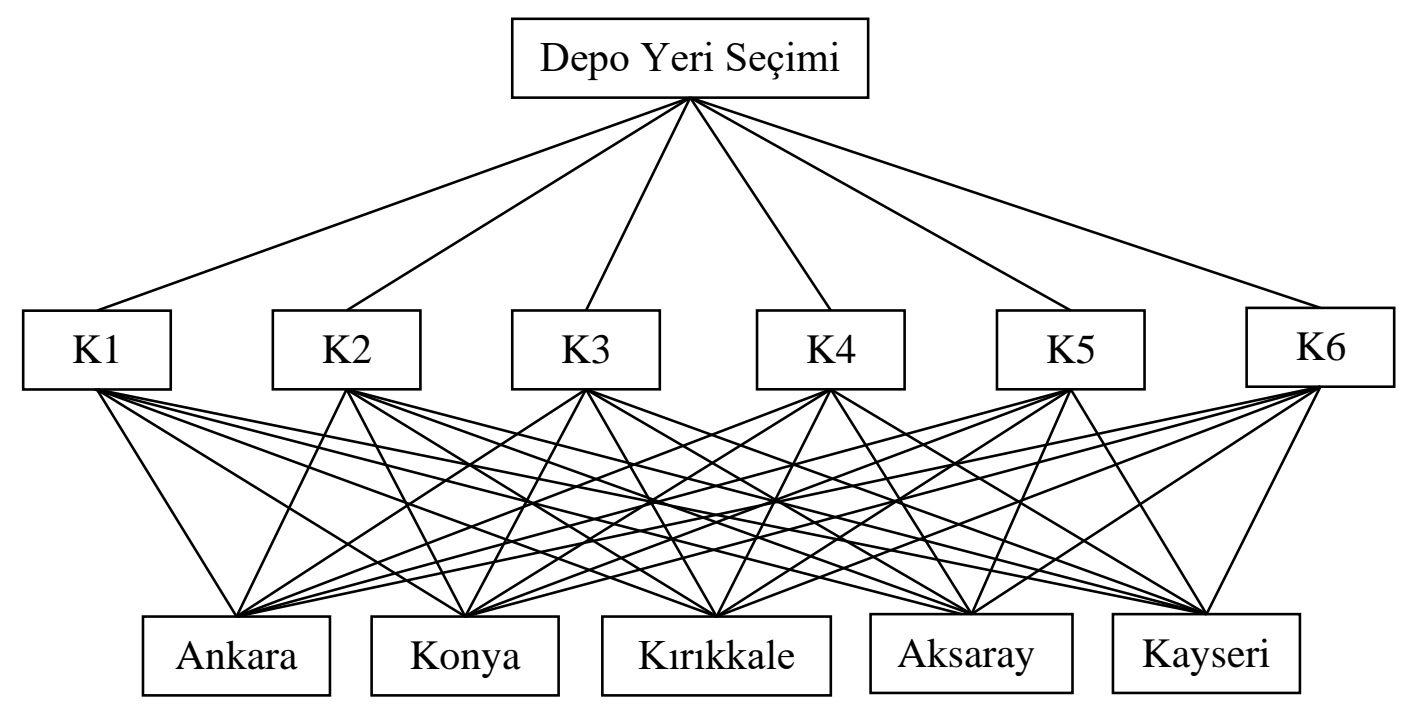

Şekil 1. Problemin Hiyerarşik Yapısı

Uzman ekibin 1-9 önem skalasını baz alarak yapılan değerlendirme sonucu oluşturulan karşılaştırma matrisinin normalize edilmiş hali Tablo 1'de gösterilmiştir.

Tablo 1. Kriter Karşılaştırmalarının Normalize Edilmesi

\begin{tabular}{|l|c|c|c|c|c|c|}
\hline Kriterler & K1 & K2 & K3 & K4 & K5 & K6 \\
\hline K1 & 0,17 & 0,16 & 0,20 & 0,12 & 0,18 & 0,19 \\
\hline K2 & 0,08 & 0,08 & 0,08 & 0,06 & 0,12 & 0,15 \\
\hline K3 & 0,33 & 0,39 & 0,40 & 0,48 & 0,37 & 0,30 \\
\hline K4 & 0,33 & 0,31 & 0,20 & 0,24 & 0,24 & 0,22 \\
\hline K5 & 0,06 & 0,04 & 0,07 & 0,06 & 0,06 & 0,11 \\
\hline K6 & 0,03 & 0,02 & 0,05 & 0,04 & 0,02 & 0,04 \\
\hline Toplam & $\mathbf{1 , 0 0}$ & $\mathbf{1 , 0 0}$ & $\mathbf{1 , 0 0}$ & $\mathbf{1 , 0 0}$ & $\mathbf{1 , 0 0}$ & $\mathbf{1 , 0 0}$ \\
\hline
\end{tabular}

Kriter ağırlıkları gerekli işlemler sonucunda Tablo 2'deki gibi hesaplanmıştır.

Tablo 2. Kriterlerin Ağırlıklarının Hesaplanması

\begin{tabular}{|l|c|}
\hline Kriterler & ĂğIlık Oranı \\
\hline K1 & 0,17 \\
\hline K2 & 0,10 \\
\hline K3 & 0,38 \\
\hline K4 & 0,26 \\
\hline K5 & 0,07 \\
\hline K6 & 0,03 \\
\hline
\end{tabular}


AHP yöntemine göre 6 kriter bazında yapılan karşılaştırmalar sonucunda alternatiflerin ağırlıkları Şekil 2'deki gibi hesaplanmıştır. Bu sonuçlara göre depo yeri seçimi için en uygun yerin Aksaray olduğu, sonrasında Kırıkkale, Ankara, Konya ve Kayseri olarak sıralandığı görülmektedir.

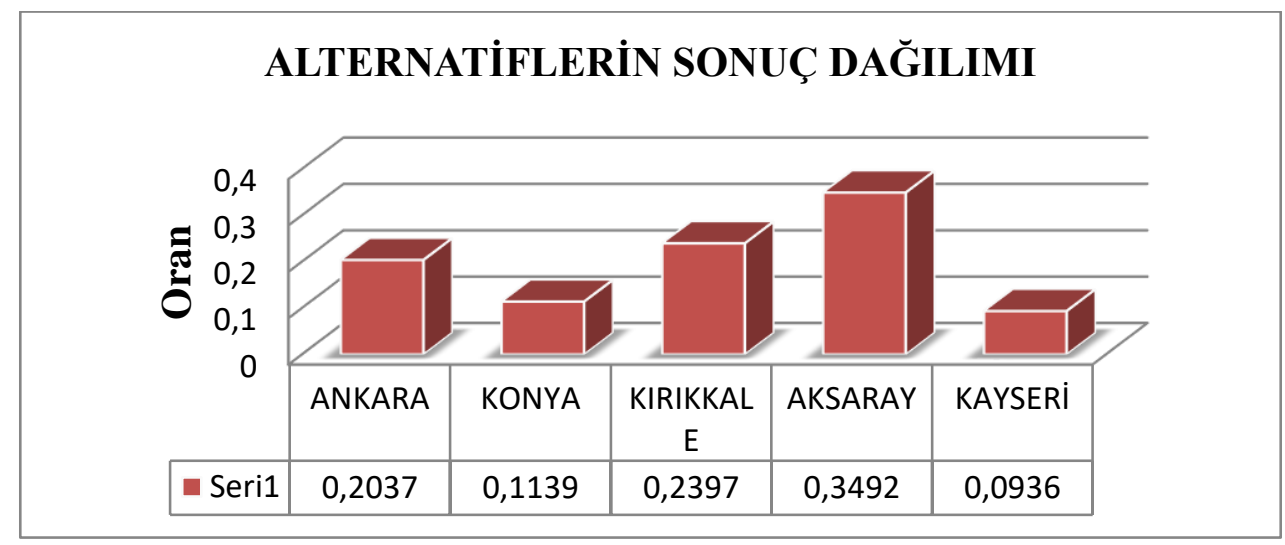

Şekil 2. Alternatiflerin Ağırlıkları

\subsubsection{AHP - TOPSIS Çözümü}

AHP yönteminde bulunan karar matrisi bu yönteme 100 ile çarpılarak puan şeklinde uyarlanmıştır. Kriterlerin önem dereceleri AHP'de belirlenen önem dereceleridir. Satırlarda karar noktaları gösterilirken sütunlarda ise kriterlere yer verilmiştir.

Tablo 3. Karar Matrisi

\begin{tabular}{|l|c|c|c|c|c|c|}
\hline & K1 & K2 & K3 & K4 & K5 & K6 \\
\hline Ankara & 6 & 43 & 19 & 21 & 43 & 5 \\
\hline Konya & 16 & 18 & 9 & 8 & 19 & 12 \\
\hline Kirıkkale & 26 & 8 & 27 & 29 & 5 & 29 \\
\hline Aksaray & 43 & 4 & 42 & 37 & 4 & 47 \\
\hline Kayseri & 9 & 27 & 5 & 5 & 29 & 7 \\
\hline
\end{tabular}

TOPSIS yöntemine göre nihai çözüm Tablo 4'de gösterilmiştir. \%79 derecelik önemle Aksaray ili ilk sırada çıkmıştır. Kırıkkale önem derecesi \%58 ile 2. sırada, Ankara ise \%41 önem derecesi ile 3. sırada yer almıştır. Deponun Aksaray’a kurulması önerilir.

Tablo 4. İdeal Çözüme Göreli Yakınlık ve Tercih Sıralaması

\begin{tabular}{|l|c|c|}
\hline & $\boldsymbol{C}_{\boldsymbol{i}}^{*}$ & Siralama \\
\hline Ankara & 0,409 & 3 \\
\hline Konya & 0,1556 & 4 \\
\hline Kırıkkale & 0,5804 & 2 \\
\hline Aksaray & 0,795 & 1 \\
\hline Kayseri & 0,1395 & 5 \\
\hline
\end{tabular}




\subsubsection{AHP - PROMETHEE Çözümü}

Problemin PROMETHEE ile çözümünde kullanılacak başlangıç matrisi ve ağırlıklar AHP yönteminde elde edilen verilerden alınmıştır. PROMETHEE yönteminin uygulanmasında Visual PROMETHEE Academic Edition programı kullanılmış ve PROMETHEE I ve PROMETHEE II çözümlerine göre değerlendirilmiştir.

K1'den K6'ya kadar olan 6 kriter ve 5 alternatif programda tanımlanmıştır. Alternatif kriter karşılaştırma matrisinde AHP de bulduğumuz verileri girerek ve nicel veriler için v-shape, nitel veriler için u-shape fonksiyonları seçilerek sonuçlar elde edilmiştir.

Şekil 3'te verilen kriter ağırlıklarına göre en iyiden en kötüye doğru bir sıralama görülmektedir. PROMETHEE I e göre en uygun depo yerinin Ankara ve Aksaray'dan hangisi olduğu net anlaşılamamaktadır. Ayrıca Konya ile Kayseri de net olarak kıyaslanamamaktadır. Bunun için PROMETHEE II analizi gereklidir.

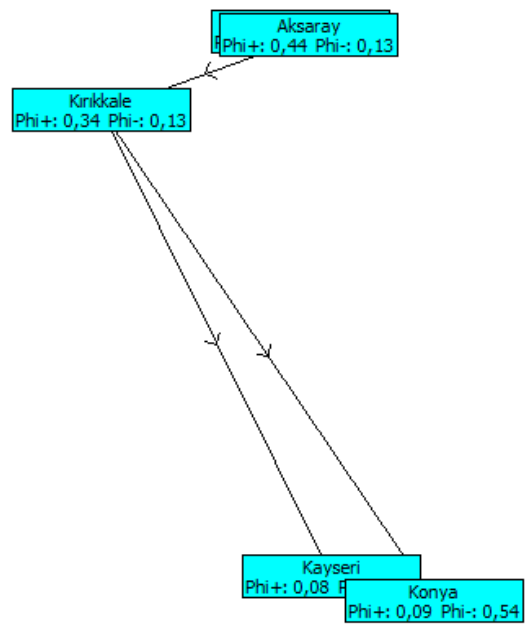

Şekil 3. PROMETHEE I İle Kısmi Sıralama Sonuçları

Şekil 4'te Pozitif üstünlüklerden negatif üstünlükler çıkartılarak PROMETHEE II ile tam sıralama elde edilmiştir. Yapılan tam sıralamaya göre en iyi alternatif Ankara olarak belirlenmiş ve sırasıyla Aksaray, Kırıkkale, Kayseri ve Konya olarak sıralanmıştır.

\begin{tabular}{c|l|l|r|r|r|}
\hline Rank & \multicolumn{2}{|c|}{ action } & Phi & Phi+ & Phi- \\
\hline $\mathbf{1}$ & Ankara & $\square$ & 0,3208 & 0,4431 & 0,1222 \\
\hline $\mathbf{2}$ & Aksaray & $\square$ & 0,3166 & 0,4428 & 0,1262 \\
\hline $\mathbf{3}$ & Kirkkale & $\square$ & 0,2154 & 0,3431 & 0,1277 \\
\hline $\mathbf{4}$ & Kayseri & $\square$ & $-0,4106$ & 0,0844 & 0,4950 \\
\hline $\mathbf{5}$ & Konya & $\square$ & $-0,4423$ & 0,0930 & 0,5353 \\
\hline
\end{tabular}

Şekil 4. PROMETHEE II ile Nihai Sıralama Sonuçları

\subsection{Sonuçların Karşılaştırılması}


Depo yeri seçimi problemine ilişkin ÇÖKV yöntemlerinden 3 tanesi kullanılarak alternatifler arasından en iyisi seçilmesi amaçlanmıştır. AHP yöntemine göre, en uygun depo yeri Aksaray olarak hesaplanmıştır. AHP-TOPSIS yöntemine göre yine Aksaray en uygun yer olarak karşımıza çıkmaktadır. 2 çözümde de Aksaray ilini sırasıyla Kırıkkale, Ankara, Konya ve Kayseri takip etmektedir. AHP-PROMETHEE yöntemine göre ise Ankara alternatifi çok az farkla Aksaray ilinin önünde en uygun yer olarak görülmektedir. Farkın bu kadar az olması ve diğer 2 çözüme göre de Aksaray’ın en iyi alternatif olarak bulunması göz önünde bulundurularak, depo yeri için Aksaray alternatifi uygundur.

\section{Sonuç ve öneriler}

Bu çalışmada, İç Anadolu Bölgesi'ne yapılması planlanan depo için, en iyi depo yerinin seçimi problemi ele alınmıştır. ÇÖKV yöntemlerinden AHP, AHP-TOPSIS ve AHP-PROMETHEE metotları kullanılarak 5 alternatif il arasından en uygun olanı seçilmiştir. Uzman görüşlerine göre belirlenen seçim kriterlerinin ağırlıklandırılmasında AHP tekniği kullanılmıştır ve tüm yöntemlerde bu ağırlıklar baz alınmıştır. AHP ve AHP-TOPSIS çözümlerine göre Aksaray alternatifi, AHP-PROMETHEE yöntemine göre Ankara alternatifi Aksaray'a yakın bir değerle en iyi depo yeri olarak bulunmuştur. Bu çözümler karşılaştırıldığında Aksaray alternatifi deponun kurulması için önerilir.

İleri ki çalışmalarda ANP ile bütünleşik TOPSIS, PROMETHEE, VIKOR gibi çok ölçütlü karar verme yöntemleri en iyi depo yerinin seçilmesinde kullanılabilir ve elde edilen sonuçlar karşılaştırılabilir. Literatürde depo yer seçimi problemlerinde ANP ve PROMETHEE yöntemlerinin birlikte kullanıldığı çalışmaya rastlanmamıştır.

\section{Kaynaklar:}

[1] Özbek A, Erol E. COPRAS ve MOORA Yöntemlerinin Depo Yeri Seçim Problemine Uygulanmas1. JEBPIR 2016;2:23-42.

[2] Korpela J, Tuominen M. A Decision Aid in Warehouse Site Selection. International Journal of Production Economics 1996;45:169-180.

[3] Chen CT. A fuzzy approach to select the location of the distribution center. Fuzzy Sets and Systems 2001;118:65-73.

[4] Kahraman C, Ruan D, Ibrahim DG. Fuzzy group decision-making for facility location selection. Information Sciences 2003;157:135-153.

[5] Chen C. A Decision Model of Field Depot Location Based on the Centrobaric Method and Analytic Hierarchy Process (AHP). International Journal of Business and Managament 2009;4:71-75.

[6] Birsel A, Cerit AG. Lojistik İşletmelerinin Kuruluş Yeri Seçiminde Arazi Faktörü. İzmir Ulaşım Sempozyumu 2009.

[7] Durmuş A. Lojistikte Depo Yer Seçimine Etki Eden Faktörlerin Modellenmesi: İstanbul Örneği. Yüksek Lisans Tezi. İstanbul Teknik Üniversitesi 2010.

[8] Demirel T, Demirel NÇ, Kahraman C. Multi-Criteria Warehouse Location Selection Using Choquet İntegral. Expert Systems with Applications 2010;37:3943-3952.

[9] Özcan T, Çelebi N, Esnaf Ş. Comparative analysis of multi-criteria decision making methodologies. Expert Systems with Applications 2011;38:9773-9779. 
[10] Ashrafzadeh M, Rafiei FM, Isfahani NM, Zare Z. Application of Fuzzy Topsis Method forthe Selection of Warehouse Location: A Case Study. Interdisciplinary Journal of Contemporary Research in Business 2012;3:655-671.

[11] Çaka E. Tedarik Zinciri Yönetiminde Choquet İntegral Yöntemi İle Depo Yeri Seçimi. Yüksek Lisans Tezi. İstanbul Teknik Üniversitesi 2012.

[12] Aktepe A, Ersöz S. AHP-VIKOR ve MOORA Yöntemlerinin Depo Yeri Seçim Probleminde Uygulanmas1. Endüstri Mühendisliği Dergisi 2014;25:2-15.

[13] Karmaker CL, Saha M. Optimization of warehouse location through fuzzy multi-criteria decision making methods. Decision Science Letters 2015;4:315-334.

[14] Cömert SE, Yener F. Bir Gıda Firması İçin Bulanık Analitik Hiyerarşi Prosesi İle Depo Yeri Seçimi. Uluslararası İktisadi ve İdari Bilimler Dergisi 2016;161-177.

[15] Dey B, Bairagia B, Sarkarb B, Sanyalb SK. Warehouse location selection by fuzzy multicriteria decision making methodologies based on subjective and objective criteria. International Journal of Management Science and Engineering Management 2016;11:262278.

[16] Emeç Ş. Çok Kriterli Yer Seçimi Problemine Stokastik AHP, Bulanık MOORA ve Bulanık VIKOR yaklaşımları ve Bir Uygulama. Yüksek Lisans Tezi. Atatürk Üniversitesi Fen Bilimleri Enstitüsü 2016.

[17] Gołda IJ, Izdebski M. The Multi-criteria Decision Support in Choosing the Efficient Location of Warehouses in the Logistic Network. Procedia Engineering 2017;87:635-640.

[18] Gül E, Eren T. Lojistik Dağıtım A ğ Problemlerinde Analitik Hiyerarşi Prosesi Yöntemi ve Hedef Programlama ile Depo Seçimi. Harran University Journal of Engineering 2017;2:113.

[19] Yavuz O. Depo Yeri Seçimi Probleminde Gri Sistem Teorisi ve VIKOR Yönteminin Karşılaştırmalı Analizi. İstanbul Gelişim Üniversitesi Sosyal Bilimler Dergisi 2018;5:169_ 191.

[20] Singh RK, Chaudhary N, Saxena N. Selection of warehouse location for a global supply chain: A case study. Indian Institute of Management Bangalore 2018;30:343-356.

[21] Saaty TL. The Analytic Hierarchy Process. New York: McGraw-Hill Inc; 1977.

[22] Felek S, Yuluğkural Y, Aladağ Z. Mobil İletişim Sektöründe Pazar Paylaşımının Tahmininde AHP ve ANP Yöntemlerinin Kiyaslanması. Makine Mühendisleri Odası Endüstri Mühendisliği Dergisi 2007;18:6-22.

[23] Özen Ü, Orçanlı K. Çok Kriterli Karar Verme Yöntemlerinden AHP ve Topsis'in E-Kitap Okuyucu Seçiminde Uygulanması. Uşak Üniversitesi Sosyal Bilimler Dergisi 2013;15:282-311.

[24] Özdemir M. Çok Kriterli Karar Verme Yöntemleri. Bursa: Dora Yayınları; 2014.

[25] Brans JP, Vincke P. A Preference Ranking Organization Method: The PROMETHEE Method for MCDM. Management Science 1985;31:647-656.

[26] Dağdeviren M, Eraslan E. Promethee Sıralama Yöntemi İle Tedarikçi Seçimi. Gazi Üniversitesi Mühendislik Mimarlık Fakültesi Dergisi 2008;23:69-75.

[27] Can T, Çilingirtürk M, Koçak H. Dışbükey Programlama İle Lojistik Merkezi Tespiti. İstanbul Üniversitesi İşletme İktisadı Enstitüsü Yönetim Dergisi 2006;54:17-25.

[28] Zak J, Weglinski S. The Selection of The Logistics Center Location Based on MCDM/A Methodology. Transportation Research Procedia 2014;3:555-564. 